\title{
RECHTSREGEL
}

Jurnal Ilmu Hukum Vol 2, No. 2 Desember 2019

P-ISSN 2622-6235, E-ISSN 2622-6243

rjih_fh@unpam.ac.id

\section{TANGGUNG JAWAB PENGANGKUT PADA PERJANJIAN PENGANGKUTAN BARANG MELALUI LAUT DITINJAU DARI PASAL 468 KUHD TENTANG PENGANGKUTAN BARANG. (Analisa Putusan Mahkamah Agung Nomor 2316 K/Pdt/2015)}

\author{
Lukas Yance Putra Posende \\ Fakultas Hukum Universitas Pamulang \\ Email: lposende@gmail.com
}

Received: 18 Sept 2019/Revised: 15 Okt 2019/Accepted: 20 Nov 2019

\begin{abstract}
ABSTRAK
Perjanjian pengangkutan merupakan perjanjian timbal balik, yaitu perjanjian yang menimbulkan hak dan kewajiban bagi para pihak yang mengadakan perjanjian tersebut, yang dalam hal ini ialah pengangkut dan pengirim barang. Dalam undang-undang nasional maupun konvensi internasional telah diatur ketentuan-ketentuan mengenai tanggung jawab dalam proses pengangkutan. Sebagaimana dinyatakan pada Pasal 468 ayat (2) Kitab Undang-Undang Hukum Dagang (KUHD), bahwa kewajiban pengangkut yang utama ialah menyelenggarakan pengangkutan dan menjaga keselamatan barang yang diangkut mulai diterimanya dari pengirim sampai diserahkannya kepada penerima barang. berdasarkan Putusan Mahkamah Agung Nomor 2316 K/Pdt/ 2015 dan untuk mengetahui apakah putusan hakim sudah memenuhi nilai keadilan atau tidak. Hasil tanggung jawab pengangkut pada penelitian ini, yaitu pengirim barang (Shipper) atau ekspidetur adalah Stavis Seafood lnc, yang mestinya bertanggung jawab atas pengiriman barang (cargo) dan harus digugat oleh penggugat yang beralamat di Boston, Amerika Serikat sesuai dengan Bill of Lading sebagai perjanjian pengangkutan. Pihak pengangkut yang mengoperasikan kapal, yang juga mesti digugat oleh penggugat. Bill of Lading juga di keluarkan di Boston, Amerika Serikat, tempat pelabuhan pemuatan barang juga di Boston, Amerika Serikat. Berdasarkan fakta-fakta hukum yang diperkuat dengan bukti-bukti yang sah, maka Pengadilan Negeri Medan tidak berwenang memeriksa dan mengadili perkara ini, sehingga gugatan terbanding/penggugat wajib ditolak atau setidak-tidaknya tidak dapat diterima. Maka telah terbukti bahwa Putusan Pengadilan Tinggi Medan Nomor 40/PDT/2014/PT MDN tanggal 24 April 2014 juncto Putusan Pengadilan Negeri Medan Nomor 666/Pdt.G/2012/PN Mdn telah salah dan keliru menerapkan hukum atau telah melakukan pelanggaran hukum, sehingga putusan dimaksud adalah batal dan tidak sah.
\end{abstract}




\section{Kata kunci: Perjanjian, Pengangkutan, Putusan Pengadilan}

\section{ABSTRACT}

The Agreement in shipping is a reciprocal agreement, which raises rights and obligation to both parties in agreement, which in this study cases are the shipper and the carrier. In one side, the carrier want to carry out obligation as small as possible, in the other side the shipper wants to delegate obligation as much as possible to the carrier. Because of the possibility of that abuse in the national law as well as international convention has been stipulated provisions in the regulations regarding the obligation in shipping procedure. As stated in Pasal 468 ayat (2) Kitab Undang-Undang Hukum Dagang (KUHD), that the first obligation of carriers are to carry out transportation and to safe guard the goods that are shipped from the beginning of receiving goods until it is handed over to the recipient. The purpose of this research is to discover the obligation liability of the parties in executing an shipping agreement by sea based on the verdict of Mahkamah Agung Nomor $2316 \mathrm{~K} / \mathrm{Pdt} 2015$ and to discover are the verdicts passed by the judge has fulfilled the value of justice or not. This research is based on normative studies, which is legal research done by researching reference materials or secondary data as basic research data by regulations and literatures that are related to the problem of interest. The result of obligation that is carried by the carrier in this research, are the Shipper or the forwarding agent Stavis Seafood Inc, is supposedly responsible for the cargo and must be sued by the plaintiff which is addressed in Boston, United States according to the Bill of Lading as an agreement of shipping. The Carrier parties which operates the ship, also must be sued by the plaintiff. Bill of Lading also released in Boston, United States, which is also where the port of the loaded goods located. Based on the legal facts which is strengthen by the valid evidence, then the State Court of Medan are not authorized to inspect or pass a verdict in this matter, therefor the lawsuit of the appealed / plaintiff must be rejected or at least can't be received. Then it has been proven that the Sentence by the High Court of Medan Nomor 40/PDT/2014/PT MDN at the 24th April 2014 corresponding with the Sentence of the State Court of Medan Nomor 666/Pdt.G/2012/PN Mdn was in valid and thus violating the law, so that the verdict is canceled.

Keyword: The agreement, Carrier, Court Decision 


\section{PENDAHULUAN}

Pengangkutan berasal dari kata angkut yang berarti mengangkat dan membawa, memuat atau mengirimkan. Pengangkutan artinya usaha membawa, mengantar atau memindahkan orang atau barang dari suatu tempat ke tempat yang lain. ${ }^{1}$

Menurut Hasim Purba di dalam bukunya "Hukum Pengangkutan Di Laut", pengangkutan adalah "kegiatan pemindahan orang dan atau barang dari suatu tempat ke tempat lain baik melalui angkutan darat, angkutan perairan maupun angkutan udara dengan menggunakan alat angkutan. Jadi pengangkutan itu berupa suatu wujud kegiatan dengan maksud memindahkan barang-barang atau penumpang (orang) dari tempat asal ke suatu tempat tujuan tertentu". ${ }^{2}$

Menurut Sudikno Mertokusumo, bahwa "Perjanjian adalah perbuatan hukum antara dua orang atau lebih yang mengikatkan diri berdasarkan kata sepakat untuk menimbulkan akibat hukum". ${ }^{3}$

Menurut Abdulkadir Muhammad Rumusan Pasal 1313 KUH Perdata tersebut mengandung kelemahan, karena seharusnya perngertian "perjanjian adalah suatu perbuatan hukum dengan mana satu orang atau lebih saling mengikatkan diri terhadap satu orang atau lebih". ${ }^{4}$

Menurut R. Subekti yang dimaksud dengan wanprestasi adalah apabila si berutang (debitur) tidak melakukan apa yang diperjanjikan.

\footnotetext{
${ }^{1}$ Departemen Pendidikan dan Kebudayaan, Kamus Besar Bahasa Indonesia, cetakan ketujuh edisi II, Balai Pustaka Jakarta, 1996, hal. 45

${ }^{2}$ Hasim Purba, Hukum Pengangkutan Di Laut, Pustaka Bangsa Press, 2005

${ }^{3}$ Sudikno Mertokusumo, Mengenal Hukum Perjanjian, Yogyakarta: Liberty, 1999, hal. 6

${ }_{4}^{4}$ Abdulkadir Muhammad, Hukum Perikatan, Bandung: Alumni, 1982, hal. 77
} 
Ia lalai atau alpa, ingkar janji atau juga ia melanggar perjanjian, apabila melakukan atau berbuat sesuatu yang tidak dilakukannya. ${ }^{5}$

Wiwoho Soedjono, dalam bukunya yang berjudul Hukum Pengangkutan Laut di Indonesia dan Perkembangannya, menyatakan:

"Perjanjian pengangkutan itu dapat dirumuskan sebagai suatu peristiwa yang telah mengikat seseorang untuk melaksanakan pengangkutan penyeberang laut karena orang tersebut telah berjanji untuk melaksanakannya, ${ }^{6}$ sedang orang lain telah pula berjanji untuk melaksanakan sesuatu hal yang berupa memberikan sesuatu yang berupa pemberian imbalan (upah), karena perjanjian itu menyangkut dua pihak, maka perjanjian demikian itu disebut perjanjian timbal balik dan karenanya menimbulkan hak dan kewajiban bagi masingmasing pihak". ${ }^{7}$

Menurut Sudjatmiko (1979) bahwa dalam pengangkutan laut tugas dan kewajiban ekspeditur mengekspedisi muatan keluar/ekspor sudah selesai jika barang sudah dimuat ke atas kapal dan bill of loding sudah diterimanya untuk diserahkan kepada pemberi kuasa (pengirim).8

Jika dilihat dari sudut teknis dan angkutanya, maka transportasi dapat dirinci menurut jenisnya sebagai berikut.

1. Angkutan jalan raya atau highway transportation (road transportation).

2. Pengangkutan rel (rail transportation).

3. Pengangkutan melalui air di pedalaman (inland transportation).

${ }^{5}$ R. Subekti, Aneka Perjanjian, Bandung: Alumni, 1977, hal. 45

${ }^{6}$ Susanto, S., \& Iqbal, M. (2019, January). Efektifitas Peranan Hukum dalam Pengelolaan Dana Desa Melalui BUMDes Sebagai Perwujudan Kearifan Lokal yang Berdaya Saing Guna Meningkatkan Kesejahteraan Rakyat. In PROCEEDINGS (Vol. 1, No. 1).

7 Wiwoho Soedjono, Hukum Pengangkutan Laut di Indonesia dan Perkembangannya, Yogyakarta : Liberty, 1987, Cet. Ke-1, hal. .22

8 Muhammad Abdul Kadir, Hukum Pengangkutan Udara, Laut dan Darat, Bandung: Citra Aditya Bakti, 1994, hal. 35 
4. Pengangkutan pipa (pipe line transportation).

5. Pengangkutan laut dan samudera (ocean transportation).

6. Pengangkutan udara (transportation by air or air transportation). ${ }^{9}$

Seperti dalam kasus yang tertulis dalam Putusan Mahkamah Agung Nomor 2316 K/Pdt/2015 di mana sebelumnya dalam Putusan Banding di Pengadilan Tinggi Medan, bahwa Pengadilan Tinggi Medan telah salah dan keliru menerapkan hukum dalam Putusannya yang menguatkan begitu saja putusan Pengadilan Negeri Medan (Judex Facti) (Majelis Hakim Pengadilan Tingkat Pertama) karena telah tidak mempertimbangkan fakta-fakta hukum yang sebenarnya yang disampaikan oleh Pemohon Kasasi/dahulu Pembanding/semua Tergugat sebagai berikut: Gugatan Terbanding/Penggugat mestinya tidak diajukan di Pengadilan Negeri Medan, tetapi di Pengadilan Boston, Amerika Serikat yang paling layak mengadili perkara ini, karena sesuai dengan bukti T-1 dan T-2, telah terbukti fakta-fakta hukum sebagai berikut:

1. Pengirim barang (Shipper) atau ekspeditur adalah Stavis Seafood inc, yang mestinya bertanggung jawab atas pengiriman barang (cargo) dan harus digugat oleh Penggugat yang beralamat di Boston, Amerika Serikat sesuai dengan Bill of Lading sebagai perjanjian Pengangkutan;

2. Pihak Pengangkut yang mengoperasikan kapal, yang juga mesti digugat oleh Penggugat dan dibuktikan kesalahannya bila ada, quod non, dalam mengangkut barang (cargo) dimana Hanjin Logistics juga berada dan beraktivitas di Amerika Serikat;

3. Bill of Lading juga di keluarkan di Boston, Amerika Serikat;

4. Tempat Pelabuhan Pemuatan Barang juga di Boston, Amerika Serikat;

${ }^{9}$ Prof.Drs.H.Rustian Kamaluddin, Ekonomi Transportasi Karasteristik, Teori, dan Kebijakan. Ghalia Indonesia, hal. 16 


\section{PERMASALAHAN}

1. Bagaimana pertanggung jawaban para pihak dalam pelaksanaan perjanjian pengangkutan melalui laut berdasarkan Putusan Mahkamah Agung Nomor 2316 K/Pdt/2015?

2. Apakah putusan hakim yang berdasarkan Putusan Mahkamah Agung Nomor 2316 K/Pdt/2015 sudah memenuhi nilai keadilan?

\section{METODE PENELITIAN}

1. Penelitian ini bersifat yuridis normatif, yaitu penelitian hukum yang dilakukan dengan cara meneliti bahan pustaka atau data sekunder sebagai bahan dasar untuk diteliti dengan cara mengadakan penelusuran terhadap peraturan-peraturan dan literatur-literatur yang berkaitan dengan permasalahan yang diteliti.

2. Pendekatan kepustakaan, yang mencakup penelitian yang berkaitan dengan materi yang dibahas serta bahan bacaan lainnya yang ada hubungannya dengan judul dari skripsi tersebut.

3. Deskriptif Analisis, menurut (Sugiono: 2009; 29) adalah suatu metode yang berfungsi untuk mendeskripsikan atau memberi gambaran terhadap objek yang diteliti melalui data atau sampel yang telah terkumpul sebagaimana adanya tanpa melakukan analisis dan membuat kesimpulan yang berlaku untuk umum.

\section{PEMBAHASAN}

\section{Tanggung Jawab Pengangkutan Barang Melalui Laut}

Menurut Pasal 468 KUHD Tentang Pengangkutan Barang "Persetujuan pengangkutan mewajibkan si pengangkut untuk menjaga akan keselamatan barang yang harus di angkutnya, mulai saat diterimanya hingga saat diserahkannya barang tersebut. Si 
pengangkut diwajibkan mengganti segala kerugian yang disebabkan karena barang tersebut seluruhnya atau sebagian tidak dapat diserahkannya, atau karena terjadi kerusakan pada barang itu, kecuali apabila dibuktikannya bahwa tidak diserahkannya barang atau kerusakan tadi disebabkan oleh suatu malapetaka yang selayaknya tidak dapat dicegah maupun dihindarkannya, atau cacat daripada barang tersebut, atau oleh kesalahan dari si yang mengirimkannya. Ia bertanggung jawab untuk perbuatan dari segala mereka, yang dipekerjakannya, dan untuk segala benda yang dipakainya dalam menyelenggarakan pengangkutan tersebut."

Sesuai dengan fakta hukum dalam Bill of Lading sebagai perjanjian pengangkutan dan sesuai dengan praktek pengangkutan laut yang berlaku umum, dapat diterangkan hubungan hukum antara pihak yang terikat secara langsung dengan Bill of Lading. Pihak Stavis Seafood, lnc sebagai pengirim barang (ekspeditur) punya hubungan langsung dengan pihak pengangkut yang mengoperasikan kapal container, dimana pihak ekspeditur membayar uang sewa kepada pengangkut dan pengangkut punya kewajiban mengangkut barang sampai ke tujuan untuk di terima oleh PT. Toba Surimi Industries sebagai penerima barang (consignee). Sedangkan pihak penerima barang punya hubungan langsung dengan pihak pengirim barang (ekspeditur), dimana barang yang dikirim atas permintaan penerima barang kepada pengirim barang (ekspeditur).

Adapun pihak Pembanding/Tergugat (PT. Bumi Hanjaya Logistic), selain bukan pihak pengirim barang (ekspeditur), juga bukan pengangkut, tetapi hanya merupakan pihak sebagai forwading agen yang memberikan jasa pengurusan kapal maupun barang di pelabuhan Belawan sebagai Pelabuhan tempat penerimaan barang.

Jadi seharusnya yang bertanggung jawab akan kasus ini adalah Pihak Satvis Seafood, lnc sebagai pengirim barang dan Hanjin Logistic 
sebagai pengangkut barang, yang seharusnya digugat dalam perkara ini untuk mempertanggung jawabkan kerugian Termohon Kasasi dahulu Penggugat/Terbanding (PT. Toba Surimi Industries) sesuai pasal 468 KUHD tentang pengangkutan barang.

\section{Hasil Penelitian}

PT Toba Surimi Industries adalah salah satu perusahaan yang bergerak dalam bidang pengalengan dan pembekuan hasil laut, dan didirikan berdasarkan hukum Negara Replubik Indonesia, yang berkedudukan di Jalan Pulau Pinang 2, Kawasan Industri Medan II, Saentis-Deli Serdang, Sumatera Utara.

Bahwa pada awalnya PT Toba Surimi Industries ada mengirim 1 (satu) unit container berisikan Canned Pasteurized Crabmeat: 24.000 lbs., Net Weight: 10,880 Kgs, Gross Weight: 13,800 Kgs kepada pembeli di Boston-USA yaitu Stavis Seafoods lnc. Namun pembeli tersebut mengalami kesulitan untuk mendistribusikannya di Amerika oleh karena terdapatnya kesalahan cetak label pada Canned Pasteurized Crabmeat.

Bahwa atas kesalahan cetak label pada Canned Pasteurized Crabmeat tersebut, lalu kemudian PT Toba Surimi Industries meminta Stavis Seafoods lnc. Boston-USA untuk mengembalikan (meretur) terhadap 1 (satu) unit container berisikan Canned Pasterurized Crabmeat: 24.000 lbs, Net Weight: 10,880 Kgs, Gross Weight: 13,800 Kgs dimaksud, untuk diadakan perbaikan terhadap kesalahan cetak label pada Canned Pasteurized Crabmeat dengan maksud dan tujuan untuk dilakukan pengemasan ulang dan selanjutnya akan dieksport kembali ke Stavis Seafoods lnc. Boston-USA.

Bahwa kemudian pada saat Stavis Seafoods lnc. Boston-USA akan mengembalikan (meretur) terhadap 1 (satu) unit container berisikan Canned Pasterurized Crabmeat: 24.000 lbs, Net Weight: 10,880 Kgs, 
Gross Weight: 13,800 Kgs untuk diadakan perbaikan terhadap kesalahan cetak label pada Canned Pasteurized Crabmeat dimaksud, maka PT Toba Surimi Industries memakai jasa/service PT Bumi Hanjaya Logistics untuk mengurus handling pengiriman terhadap Canned Pasterurized Crabmeat: 24.000 lbs, Net Weight: 10,880 Kgs, Gross Weight: 13,800 Kgs dari Stavis Seafoods lnc. Boston-USA kepada PT Toba Surimi Industries.

Bahwa dalam melakukan pengiriman tersebut PT Toba Surimi Industries menginstruksikan kepada PT Bumi Hanjaya Logistics untuk menjaga temperature atau suhu container tersebut di suhu kurang lebih 0,5 derajat celcius, sebagaimana diuraikan dalam Bill Of Lading Intruction, BKG Nomor NYC211446400 juncto Bill Of Landing Nomor HJLNYC12050066, dimana telah secara tegas dan jelas disebutkan bahwa "The Cargo is stowed in a reefer container at the temperature of 32,9 Degrees Fahrenheit, Temperature set at Plus 0,5 Degrees Celcius" yang artinya bahwa "kargo dimuat di container refeer pada suhu 32,9 derajat Fahrenheit atau 0,5 derajat celcius" dan terhadap hal tersebut PT Bumi Hanjaya Logistics menyatakan persetujuannya, terbukti bahwa PT Bumi Hanjaya Logistics yang melakukan handling pengiriman tersebut kepada PT Toba Surimi Industries.

Selama dalam perjalanan pengiriman terhadap 1 (satu) unit container berisikan Canned Pasterurized Crabmeat: 24.000 lbs, Net Weight: 10,880 Kgs, Gross Weight: 13,800 Kgs dari Stavis Seafoods lnc. Boston-USA kepada PT Toba Surimi Industries yang memakan waktu kurang lebih 2 (dua) bulan lamanya (dari tanggal 15 Juni 2012 s/d tanggal 8 Agustus 2012), ternyata terjadi tindakan/perbuatan kelalaian yaitu tidak menjaga secara baik dan benar pengaturan/pemberian temperature atau dengan kata lain pengaturan/pemberian temperature telah melebihi ambang batas yang 
dikehendaki oleh PT Toba Surimi Industries sebagaimana dimaksud dalam Bill Of Lading Nomor HJLTNYC12050066, apabila diperbandingkan dengan hasil alat perekam temperature/Temperatur Recorder sebanyak 3 (tiga) unit yang diletakkan di dalam countainer oleh Stavis Seafoods lnc. Boston-USA tersebut, menyebabkan pengiriman terhadap 1 (satu) unit container berisi Canned Pasterurized Crabmeat: 24.000 lbs, Net Weight: 10,880 Kgs, Gross Weight: 13,800 Kgs menjadi beku dan kwalitasnya menurun, sehingga tidak dapat dipergunakan lagi (rusak). Maka dengan demikian telah jelas dan nyata menimbulkan kerugian materil bagi PT Toba Surimi Industries sejumlah tersebut dalam Commercial Invoice "Return Cargo" yaitu 237,960 US Dollar.

Sehubungan dengan perselisihan hukum diatas, maka PT Toba Surimi Industries melalui kuasa/wakilnya dengan itikad baik telah memberikan 2 (dua) kali Surat Peringatan kepada PT Bumi Hanjaya Logistics, sebagaimana masing-masing Surat Peringatan tertanggal 02 Oktober 2012, Nomor 258/CA-SK/IX/2012, Lamp: 1 (satu) set, Perihal: Peringatan dan Surat Peringatan Terakhir tertanggal 12 Oktober 2012, Nomor 264/CA-SK/X/2012, Lamp: - Perihal: Peringatan Terakhir dengan maksud dan tujuan agar terhadap perselisihan hukum dimaksud dapat diselesaikan secara musyawarah dan kekeluargaan. Akan tetapi terhadap itikad baik tersebut tidak mendapat respon yang positif, dimana jika dihitung mulai sejak surat peringatan tertanggal 2 Oktober 2012 sampai dengan gugatan ini didaftarkan ke Kepaniteraan Pengadilan Negeri Medan, maka telah kurang lebih 1 (satu) bulan dan 26 (dua puluh enam) hari lamanya waktu yang ada bagi Tergugat PT Bumi Hanjaya Logistics untuk dapat melakukan investigasi serta pengumpulan data-data guna menyelesaikan permasalahan hokum dimaksud. Oleh karenanya dengan alasan-alasan tersebut diatas, sehingga akhirnya Penggugat PT Toba Surimi Industries melalui 
kuasa/wakilnya mendaftarkan gugatan ini ke Kepaniteraan Pengadilan Negeri Medan untuk proses penyelesaiannya.

Kerugian yang diamali oleh Penggugat yaitu PT Toba Surimi Industries yaitu:

1. Nilai harga jual terhadap 1 (satu) unit container berisi Canned Pasteurized Crabmeat: 24.000 lbs, Net Weight: 10,880 Kgs, Gross Weight: 13,800 Kgs, sesuai Commercial Invoice "Return Cargo" yaitu 237,960 US Dollar.

2. Biaya Pengapalan atas pengiriman terhadap 1 (satu) unit container berisi Canned Pasteurized Crabmeat: 24.000 lbs, Net Weight: 10,880 Kgs, Gross Weight: 13,800 Kgs, dari Stavis Seafoods lnc. BostonUSA kepada Penggugat PT Toba Surimi Industries sebesar 15,100 US Dollar

3. Bunga dari nilai Commercial Invoice "Return Cargo", dan Biaya Pengapalan tersebut sebesar setara bunga bank, yaitu 1\% (satu persen) perbulan $\mathrm{x}(237,960 \mathrm{USD}+15,100 \mathrm{USD})=1 \% \mathrm{x} 253,060$ USD atau sebesar yang patut menurut pertimbangan rasa keadilan hokum dan rasa keadilan umum Pengadilan Negeri Medan, terhitung sejak tanggal Surat Peringatan dari kuasa/wakil yaitu tanggal 02 Oktober 2012 sampai dengan tanggal nilai Commercial Invoice "Return Cargo", dan Biaya Pengapalan tersebut dibayar lunas oleh Tergugat kepada Penggugat.

Oleh karena Tergugat telah terbukti melakukan tindakan/perbuatan cidera janji (wanprestasi) terhadap Penggugat, sehingga dengan demikian telah menimbulkan hak normative bagi Penggugat untuk menuntut ganti kerugian seperti terurai diatas, bahwa sejalan dengan hal tersebut, maka Yurispridensi Mahkamah Agung Replubik Indonesia Nomor 716 K/Pdt/1984 tanggal 5 September 1985 yang memberi kaidah hukum bahwa "Tanggung jawab seorang pengangkut terhadap kerusakan barang yang timbul selama 
pengangkutan hanyalah terbatas sampai pada jumlah yang diperjanjikan dalam Bill Of Lading/Konosemen”. Bahwa lebih lanjut Yurispridensi Mahkamah Agung Replubik Indonesia Nomor 409 K/Sip/1983 tanggal 25 Oktober 1984 yang memberi kaidah hukum bahwa "Pada azasnya seorang pengangkut harus bertanggung jawab sepenuhnya atas barang-barang yang diangkutnya sejak diterima sampai diserahkannya barang-barang yang diangkut tersebut kepada yang berhak dan juga seorang pengangkut harus mengganti kerugian sebagian atau seluruhnya dari tidak dapat diserahkannya barangbarang tersebut, kecuali ia dapat membuktikan bahwa tidak dapat diserahkannya barang tersebut atau kerusakan barang adalah suatu akibat malapetaka yang secara patut ia tidak dapat mencegahnya".

Penggugat mempunyai sangka yang beralasan dan karenanya Penggugat khawatir bahwa Tergugat berupaya untuk mengalihkan dan atau menyembunyikan harta kekayannya guna menghindari tanggungjawabnya atas tuntutan Penggugat tersebut, oleh karena itu Penggugat mohon dengan hormat perkenan Pengadilan Negeri Medan untuk meletakkan sita jaminan (conservatoir beslag), atas harta benda milik Tergugat, yaitu:

1. 1 (satu) unit bangunan permanen berikut tanah dan pertapakannya terletak di Jalan Kolonel Sugiono Nomor 10-G Medan, setempat dikenal dengan kantor PT. Bumi Hanjaya Logistics

2. 1 (satu) unit bangunan permanen berikut tanah dan pertapakannya terletak di Kompleks Multatuli Indah Blok B Nomor 30 Medan, setempat dikenal kantor PT. Bumi Hanjaya Logistics

Gugatan Penggugat ini didukung oleh bukti-bukti yang sah, kuat, dan cukup, serta atas dasar hukum yang sahih, sehingga oleh karenanya cukup alasan hukum jika Penggugat mohon kepada Pengadilan Negeri Medan untuk: 
1. Menyatakan putusan perkara ini dapat dijalankan secara terlebih dahulu (uit voerbaar bij voorraad) walaupun ada perlawanan, banding maupun kasasi

2. Menghukum Tergugat untuk membayar ongkos perkara ini

Berdasarkan alsan-alasan tersebut di atas Penggugat mohon kepada Pengadilan Negeri Medan agar memberikan putusan sebagai berikut:

Primair

1. Menerima dan mengabulkan gugatan Penggugat seluruhnya;

2. Menyatakan sah dan berharga sita jaminan (conservatoir beslag) yang telah diletakkan dalam perkara ini;

3. Menyatakan demi hukum bahwa Tergugat telah cidera janji (wanprestasi);

4. Menghukum Tergugat untuk mengganti secara tunai seluruh kerugian Penggugat yang disebutkan pada posita gugatan point 12;

5. Menyatakan putusan perkara ini dapat dijalankan secara terlebih dahulu (uit voerbaar bij voorrraad) walaupun ada perlawan, banding maupun kasasi;

6. Menghukum Tergugat untuk membayar ongkos-ongkos perkara yang timbul dalam perkara ini;

Subsidair Atau apabila Pengadilan berpendapat lain mohon diambil putusan yang seadil-adilnya (ex a quo et bono);

Bahwa terhadap gugatan tersebut Tergugat mengajukan eksepsi yang pada pokoknya sebagai berikut:

1. Pengadilan Negeri Medan Tidak Berwenang

a. Bahwa gugatan Penggugat mestinya tidak diajukan di Pengadilan Negeri Medan, tetapi di Pengadilan Boston Amerika Serikat yang paling layak mengadili perkara ini, karena fakta-fakta hukum sebagai berikut: 
1) Pengirim barang (Shipper) adalah Stavis Seafood, yang mestinya bertanggung jawab atas pengiriman barang (cargo) dan harus digugat oleh Penggugat yang beralamat di Boston, Amerika Serikat sesuai dengan Bill Of Lading sebagai perjanjian Pengangkutan;

2) Pihak pengangkut yaitu: Hanjin Logistic, yang juga mesti digugat oleh Penggugat dan dibuktikan kesalahannya bila ada, quod non, dalam mengangkut barang (cargo) dimana Hanjin Logistic juga beralamat di Amerika Serikat;

3) Bill Of Lading juga dikeluarkan di Boston, Amerika Serikat;

4) Tempat pelabuhan pemuatan barang juga di Boston, Amerika Serikat;

b. Bahwa oleh karena itu, berdasarkan fakta-fakta hukum tersebut diatas yang diperkuat dengan bukti-bukti yang sah, maka Pengadilan Negeri Medan tidak berwenang memeriksa dan mengadili perkara ini, sehingga gugatan Penggugat wajib ditolak atau setidak-tidaknya dinyatakan tidak dapat diterima;

2. Kesalahan Mengenai Pihak (error in persona)

a. Bahwa Penggugat telah keliru menuntut atau menggugat Tergugat yang sama sekali tidak layak secara hukum untuk diminta bertanggung jawab atas tuntutan Tergugat dalam perkara a quo yang katanya ada kerusakan barang milik Penggugat yang diangkut dengan kapal container oleh Hanjin Logistik

b. Bahwa secara hukum, sekiranya benar ada kerusakan barang, quod non, dalam pengangkutan melalui laut, maka yang wajib bertanggung jawab adalah pihak Pengirim barang (shipper) ataupun pihak Pengangkut (carrier) yang memiliki kapal container atau sebagai pihak yang mengoperasikan kapal 
c. Bahwa adapun kedudukan Tergugat hanya sebagai Fordwading Agent sehubungan dengan pembongkaran dan penerimaan barang milik Penggugat di tempat pelabuhan bongkar yaitu Pelabuhan Belawan, Indonesia. Karena itu, tergugat tidak punya hubungan langsung dengan pihak Pemilik barang in casu Penggugat, yang menimbulkan hak dan kewajiban, tetapi Penggugat sebagai pemilik barang punya hubungan langsung dengan pengirim barang (Shipper) yaitu Stavis Seafood lnc. Yang beralamat di Boston, Amerika Serikat, sedangkan pengirim barang (Stavis Seafood lnc) punya hubungan langsung dengan pihak Pengangkut (carrier) yaitu Hanjin Logistic yang dalam pengangkutan ini beralamat di Amerika Serikat. Hubungan hukum langsung dengan Penggugat dasar Kesepakatan maupun perjanjian yang menimbulkan hak dan kewajiban, maka penggugat tidak punya dasar hukum untuk menggugat tergugat dalam perkara a quo

d. Timbulnya hak dan kewajiban maupun tanggung jawab atas suatu resiko hanya berlaku antara pihak yang mempunyai hubungan langsung atas dasar kesepakatan atau perjanjian tertulis. Karena itu, sekiranya penggugat benar, quod non, mengalami suatu kerugian karena kerusakan barang, maka secara hukum mestinya penggugat menuntut atau menggugat pihak pengirim barang (shipper) yaitu Stavis Seafood lnc atau sekiranya benar alasan penggugat bahwa kerusakan barang (cargo) miliknya di perjalanan karena masalah container, quuod non, maka hal itu merupakan urusan dan tanggung jawab pihak pengangkut (carier), sedangkan tergugat bukanlah pihak pengangkut

e. Bila mencermati dalil-dalil penggugat dalam gugatannya butir 5 s/d butir 15 gugatannya, terutama butir 8 , ternyata penggugat 
menyebutkan adanya suatu kelalaian pengangkut quod non, sehingga barang 1 (satu) unit container Canned Pasteurized Crabmeat: 24,000 lbs. Net Weight: 10,880 Kgs, Gross Weight: 13,800 Kgs milik Penggugat menjadi rusak. Juga kutipan Yurisprudensi dalam butir 6, butir 14 dan butir 15 gugatan penggugat menyebutkan soal tanggung jawab pengangkut, akan tetapi kenapa pihak tergugat menjadi yang digugat, sedangkan tergugat sama sekali tidak berkedudukan sebagai pihak pengangkut yang punya kontrak atau perjanjian pengangkutan dengan pihak pengirim barang (shipper), yaiut Stavis Seafood lns

f. Dengan demikian, tuntutan atau gugatan penggugat kepada tergugat adalah salah alamat atau keliru mengenai pihak atau orangnya (eror in persona)

\section{Gugatan Kurang Pihak}

a. Gugatan penggugat adalah kurang pihak, karena justru pihak yang sangat penting yang punya hubungan langsung dengan penggugat malahan tidak digugat oleh penggugat, sedangkan tergugat tidak punya hubungan langsung dengan penggugat

b. Penggugat sebagai penerima barang (consignee), barang mana dikirim oleh Stavis Seafood lnc sebagai pengirim barang (shippier) dari Boston, Amerika Serikat, melalui angkutan laut dengan menggunakan pengangkut (carrier) yaitu Hanjin Logistik

c. Sesuai praktek yang berlaku secara internasional, ketiga pihak tersebut yaitu pihak pengirim barang (shipper), pihak pengangkut (carrier) dan pihak penerima barang (consignee) punya kepentingan yang saling terkait langsung. Pihak pengirim barang (shipper) membuat kesepakatan dengan pihak penerima barang (consignee, in casu penggugat) mengenai syarat-syarat pengiriman barang dimana pihak penerima barang (consignee) melakukan pembayaran biaya angkutan kepada pihak pengirim 
barang (shipper). Begitu pula pihak pengirim barang (shipper) membuat kesepakatan mengenai syarat-syarat pengangkutan barang dengan pihak pengangkut (carrier) dimana pengirim barang (shipper) membayar uang angkutan barang (uang tambang) kepada pihak pengangkut (carrier)

d. Adapun pihak tergugat bukanlah pihak yang punya kepentingan dengan tergugat sehubungan dengan pengiriman barang tergugat hanya sebagai forwarding agen dari pengangkut (carrier) yang mengurus kepentingan kapal pihak pengangkut di pelabuhan tiba yaitu Belawan

e. Dengan demikian, jelas sekali bahwa gugatan penggugat yang tidak menggugat pihak pengirim barang (shipper) yaitu Stavis Seafood lnc dan pihak-pihak lainnya adalah kurang pihak, sehingga gugatan penggugat wajib ditolak atau setidak-tidaknya tidak dapat diterima.

\section{KESIMPULAN}

1. Pertanggung jawaban para pihak dalam pelaksanaan perjanjian pengangkutan melalui laut berdasarkan Putusan Mahkamah Agung Nomor 2316 K/Pdt/2015 bahwa sesuai dengan dokumen pengangkutan, pembanding/tergugat tidak punya hubungan hukum yang menimbulkan hak dan kewajiban langsung antara terbading/penggugat, yang mana terlihat dokumen konosemen/nill of lading yang merupakan perjanjian pengangkutan, adapun pihak pembanding/tergugat selain bukan pengangkut barang juga bukan pengangkut barang tetapi hanya merupakan pihak sebagai forwarding agen yang memberikan jasa pengurusan kapal maupun barang di pelabuhan Belawan sebagai Pelabuhan tempat penerimaan barang. Jadi yang berhak bertanggung jawab adalah pihak pengirim (ekspidetur) sesuai dengan Peraturan Pemerintah 
Replubik Indonesia Nomor 51 Tahun 2002 tentang Perkapalan, yang menyatakan sbb: Pasal 100 : Pengirim maupun pengangkut petikemas bertanggung jawab dan menjamin bahwa barang yang dikirim dalam petikemas sesuai dengan ketentuan yang berlaku, dan tidak melebihi batas kemampuan petikemas yang bersangkutan. Dalam Bill of Lading juga jelas tertulis bahwa PT. Toba Surimi Industries adalah Consignee (penerima barang) dan pihak pengangkut (Carrier) adalah Hanjin Logistic dan Stavis Seafood, lnc sebagai pihak pengirim barang. Jadi dalam perkara ini adanya kurang tanggung jawab antara pihak pengirim dan pihak pengangkut yang tidak menjaga keselamatan barang yang diangkut mulai diterimanya dari pengirim sampai diserahkannya kepada penerima barang.

2. Putusan hakim yang berdasarkan Putusan Mahkamah Agung Nomor 2316 K/Pdt/2015 sudah memenuhi nilai keadilan yang sebagaimana mestinya bahwa tidak benar putusan Judex Facti yang menyatakan menghukum tergugat (PT. Bumi Hanjaya Logistic) untuk mengganti secara tunai kerugian kepada penggugat (PT. Toba Surimi Industries) sebesar 253.060 USD dan menurut pertimbangan Majelis Hakim pembanding/tergugat dihukum membayar ganti kerugian dimaksud karena pembanding/tergugat adalaha agen pengirim barang (ekspidetur), adapun pengertian ekspidetur menurut pasal 86 ayat (1) menyebutkan bahwa "ekspidetur adalah seseorang yang pekerjaannya menyelenggarakan pengangkutan barang-barang dagangan dan barang-barang lain di darat atau perairan”. Jadi pertimbangan hukum dan putusan Judex Facti tersebut adalah sangat keliru, tidak berdasarkan hukum, tidak menerapkan hukum sebagaimana mestinya, dengan alasanalasan sebagai berikut: 
a. Pembanding bukanlah pihak pengirim barang atau pengangkut (yang disebut oleh Judex Facti sebagai ekspeditur). Tetapi pihak Stavis Seafood, lnc sebagai pengirim barang, yaitu barang dikirim dari Pelabuhan Boston, Amerika Serikat ke Pelabuhan Belawan, Sumatera Utara.

b. Bahwa sangat tidak adil pemohon kasasi/pembanding/tergugat dihukum bertanggung jawab untuk mengganti kerugian pada sesuatu yang diluar tugas dan tanggung jawabnya, karena pembanding/tergugat bukanlah pihak pengirim barang atau ekspeditur atau bukanlah pengangkut, tetapi pemohon kasasi/pembanding/tergugat hanyalah pihak yang menyediakan jasa pengurusan kedatangan kapal dan barang di pelabuhan belawan tempat barang tiba dari Boston, Amerika Serikat.

\section{SARAN}

1. Perusahaan yang menggunakan jasa pengangkutan laut seharusnya sudah memahami pertanggung jawabannya apabila terjadi cidera hukum, terkait dalam perjanjian pengangkutan dibuat yang telah disepakati dan perlu mencatatkan muat angkutan ke dalam dokumen muatan untuk memudahkan pembuktian. Perusahaan angkutan laut juga harus memperhatikan undang-undang yang berlaku kedepannya dalam melaksanakan kegiatan usahanya agar dapat memajukan pengangkiutan barang di laut.

2. Perusahaan pengangkutan laut saya harap kedepannya membuat ketentuan ganti rugi melihat perjanjian awal antara perusahaan angkutan dengan penumpang serta memperhatikan mekanisme ganti rugi yang sudah diatur di undang-undang agar tidak menimbulkan kerugian kepada salah satu pihak yang berkepentingan maupun tidak. 


\section{DAFTAR PUSTAKA}

\section{Buku}

A.Abdulkadir Muhammad, 1991, Hukum Pengangkutan Darat, Laut dan Udara, Bandung: Citra Aditya Bakti.

Abdulkadir Muhammad, 1982, Hukum Perikatan, Bandung: Alumni.

Departemen Pendidikan dan Kebudayaan, 1996, Kamus Besar Bahasa Indonesia, Jakarta: Balai Pustaka, cetakan ketujuh edisi II

Hasim Purba, 2005, Hukum Pengangkutan Di Laut, Pustaka Bangsa Press.

Muhammad Abdul Kadir, 1991, Hukum Pengangkut Darat, laut dan Udara, Cipta Aditya Bahkti, Jakarta,

Muhammad Abdul Kadir, 1994, Hukum Pengangkutan Udara, Laut dan Darat, Bandung: Citra Aditya Bakti.

Prof. Drs. H.Rustian Kamaludin, 2003, Ekonomi Transportasi Karateristik, Teori, dan Kebijakan, Jakarta: Ghalia Indonesia.

Purwosutjipto, 1984, Pengertian Pokok Hukum Dagang Indonesia, Jilid III, Djambatan,

R. Subekti, 1977, Aneka Perjanjian, Bandung: Alumni.

Sudikno Mertokusumo, 1999, Mengenal Hukum Perjanjian, Yogyakarta: Liberty.

Wiwoho Soedjono, 1987, Hukum Pengangkutan Laut di Indonesia dan Perkembangannya, Yogyakarta : Liberty.

\section{Peraturan Perundang-undangan}

Kitab Undang-Undang Hukum Perdata.

Kitab Undang-Undang Hukum Dagang. 